\title{
New Insights into the Molecular Basis of the House Dust Mite-Induced Allergic Response
}

\author{
Alain Jacquet* \\ Laboratory of Experimental Allergology, Universite Libre de Bruxelles, Faculte des Sciences, Institut de Biologie et de \\ Medecines Moleculaires, 6041 Gosselies, Belgium and Division of Allergy and Clinical Immunology, Chulalongkorn \\ University, Department of Medicine, Faculty of Medicine, 10330 Bangkok, Thailand
}

\begin{abstract}
House dust mite (HDM) represents world-wide one of the most common source of aeroallergens word-wide and more than $50 \%$ of allergic patients are sensitized to these allergenic molecules. Although the induction of specificTh2 cells as well as IgE by HDM is well understood, the events that control the initial Th2 polarization in response to HDM are still poorly defined. Notably, mechanisms by which HDM is recognized by the airway mucosa, interacts with barrier epithelial cells, leading to dendritic cell (DC) recruitment, activation, and subsequent Th2-mediated responses, remains to be elucidated. Moreover, whereas the allergenicity of the group 1 major mite allergens could be largely explained by their intrinsic proteolytic activity, the fundamental mechanistic question regarding the putative intrinsic allergenic properties of the group 2 major mite allergen remained unanswered to date.

This review summarizes new insights into diverse determinants that contribute to the HDM allergenicity. In addition to the auto-adjuvant capacity of the two major mite allergen Der p 1 and 2, due to proteolytic activity and functional mimicry of the Toll-like receptor 4 (TLR4) co-receptor MD2 respectively, contaminating factors derived from HDM carriers, mainly endotoxins (LPS) et $\beta$-glucans, are very important to activate the innate immune response which, in turns, is involved in the development of allergic response by HDM.
\end{abstract}

\section{INTRODUCTION}

Allergic reactions are symptomatic responses to a normally innocuous environmental antigen such as pollen, animal dander and house dust mites. The prevalence of allergic asthma, the most common allergic disease, increased dramatically in the last 50 years, ranging from 5 to $30 \%$ in the developed countries [1]. This exacerbated immunemediated disorder is characterized by chronic airway inflammation, mucus production, and variable airflow obstruction with airways hyperresponsiveness (AHR) [2].

House dust mites can be considered as a predominant provider of inhalant allergens within the world and the mite sensitization affects more than $15-20 \%$ of the population from industrialized countries [3]. The most common mite species Dermatophagoides pteronyssinus and Dermatophagoides farinae produce more than 20 different allergen groups classified according to their sequence homology and biological function [4-7]. Despite increasing knowledge about the molecular and functional characteristics of HDM allergens, little is known about the mechanisms that control the initial events of the HDM-induced allergic response.

The purpose of this review is to discuss recently identified functions of contaminating microbial compounds in

*Address correspondence to this author at the Chulalongkorn University, Division of Allergy and Clinical Immunology, Department of Medicine, Faculty of Medicine, Oor-Por-Ror Building, 10th floor, Room \# 1010/5, 1873 Rama IV Road, Pathumwan, Bangkok 10330, Thailand; Tel: +66 2 2564579; Fax: +66 2 6523100; E-mail: alain.j@chula.ac.th
HDM in the initiation of the allergic response through direct effects on the innate immune system but also through their influence on the group 2 mite allergen allergenicity. This review outlines that, in addition to the intrinsic biological functions of HDM allergens, non-allergenic factors from their carrier contribute to the HDM allergenicity

\section{CRITICAL ROLE OF TH2 CELLS IN ALLERGY AND OF DENDRITIC CELLS IN THE TH2 PRIMING}

Following contacts with inhaled antigens and depending on the susceptibility of the individual, either a healthy or an allergic immune response to the antigen arises. The normal pulmonary response to harmless airborne particles is tolerance through the action of allergen-specific Treg cells and the production of $\mathrm{IgG} 4$ or IgG1 allergen-specific antibodies [8]. There is no specific production of $\mathrm{IgE}$ and no development of airway inflammation following chronic exposure. In contrast, atopic subjects display reduced frequencies of allergen-specific Treg cells [9]. Experimental evidences suggest that allergen-specific Th2 cells play the central role for the primary mediation of the asthmatic inflammatory response [10] as an increase in Th2 lymphocytes was observed in the airways of human asthma patients and in animals sensitized and challenged with allergens [11-18]. The secretion by Th2 cells of IL-4, IL-5, IL-9, and IL-13 [19-21] and probably other recently identified cytokines, such as IL-25, IL-31, and IL-33 mediate the allergen-specific Th2 response and inflammation [22-26] characterized by the production of allergen-specific IgE, eosinophilia, the permissiveness of endothelium for the recruitment of inflammatory cells to 
inflamed lungs, the production of mucus, and the modulation of the airway smooth muscle contraction [27].

However, some studies also clearly evidenced that other $\mathrm{T}$ cell subsets, including Th1 cells, natural killer $\mathrm{T}$ (NKT) cells, Th17 cells, $\gamma \delta \mathrm{T}$ cells and $\mathrm{CD} 8+\mathrm{T}$ cells accumulate in the airway of asthmatics and may also play a role in its pathogenesis [28].

Whereas biology of Th2 cells and their importance for the immediate and chronic phases of the allergic responses are well understood, little is known about the mechanisms that control the initial Th2 polarization in response to allergens.

Many studies report that dendritic cells (DCs), the most powerful antigen presenting cells (APCs), orchestrate the induction of Th1, Th2, Th17 or Treg responses [29, 30]. Many factors are decisive in the process of Th polarization including the type of antigen, the presence of microbial compounds, the route of exposure and the genetic background of the host. All these factors will act at the level of DC to induce signals triggering Th subset cell differentiation $[2,31]$.

Consequently, airway DCs must be critical for priming and Th2 differentiation of naïve $\mathrm{T}$ cells towards aeroallergens [32]. A network of airway DCs is located just under the epithelial layer to act as sentinels for invading pathogens and inhaled antigens. DCs can sample the allergens present the airway lumen by forming dendritic extensions between epithelial cells or the allergens gain access to DCs through cleavage of tight junction proteins (see below). Aeroallergens are then captured by these DCs through endocytosis followed by their processing and their presentation to CD4 T-helper (Th) cells [33]. The allergen peptide presentation by MHC class II molecules to naïve CD4+ Th cells requires subsequent migration of DCs that have captured antigen to the $\mathrm{T}$ cell area of mediastinal lymph nodes. During this event, DCs acquire a mature phenotype characterized by the up-regulation of the co-stimulatory molecules CD80 and CD86 for naïve $T$ cell activation [34].

However, the allergen peptide presentation to TcR and the interaction of costimulatory molecules from DC with the corresponding receptors in $\mathrm{T}$ cells are insufficient to mount $\mathrm{T}$-cell responses. It requires also additional and critical regulatory signals: the presence of DC-activating cytokines produced notably by the airway epithelial cells, the cytokines released from DC as well as adjuvant factors from the microenvironment which influence these cytokine productions. It must also be pointed out that, whereas conventional DCs are important for generating $\mathrm{T}$ cell division and priming, plasmacytoid DCs (pDCs) suppress $\mathrm{T}$ cell effector generation to promote tolerance. Strikingly, exposure to harmless antigen in the absence of pulmonary pDCs led to Th2 cellinduced allergic asthma [35].

The DC-derived cytokines IL-12 and IL-10 are the key polarizing components to induce Th1 or Treg responses respectively whereas IL-6, IL-21, IL-23, IL-1 $\beta$ are skewing signals for differentiation of Th17 cells $[36,37]$. In contrast, a DC-derived cytokine skewing to Th2 was not described to date. Notably, these APCs are not able to produce the key Th2-polarizing cytokine IL-4. However, a recent observation indicated that allergen-activated basophils could be the initial source of Th2-inducing cytokines [38]. Indeed, direct activation of basophils by protease allergens lead to the recruitment of basophils to T-cell areas of draining lymph nodes during the priming phase of the response and to the production of IL-4 and Thymic stromal lymphopoietin (TSLP) which are involved in Th2 differentiation in vivo. The results clearly confirm that innate immune cells are major participants in the initiation of allergen-specific Th2 cell responses.

\section{CRITICAL ROLE OF TH2-PROMOTING ADJUVANT SIGNALS IN DC ACTIVATION}

Although the sensitization process to natural allergens remains to be fully elucidated, it is evident that, for the priming of the allergic response, DCs need to be activated by a sense of danger triggered by "adjuvant factors" from the microenvironment. These Th2-promoting adjuvant signals can derive from the intrinsic properties of the allergen itself, as clearly demonstrated with Der p 1 [39 and see below], from the allergen carriers as phytoprostanes from pollen grains or endotoxins from HDM [40, 31] or from exposures to environmental components present in air and dust such as respiratory viruses, air pollutants, cigarette smoke or microbial products $[41,42]$. All these inhaled agents could directly shape a pro-Th2 DC and/or stimulate the activation of the airway epithelium which, in turn, will communicate with DC to induce Th2-biased responses.

Consequently, to induce allergen sensitization, individuals must be not only exposed to the allergen but also to components that directly activate receptors expressed on cells of the innate immune system [43]. For example, the microbial-derived products, the so-called pathogenassociated molecular-pattern (PAMP) molecules act through recognition by pattern-recognition receptors (PRRs), including the Toll-like receptors (TLRs), NOD-like receptors (nucleotide-binding oligomerization domain containing proteins NLRs), C-type lectin receptors including Dectin, and dendritic cell-specific intercellular adhesion molecule 3-grabbing nonintegrin (DC-SIGN/CD209) [44-46].

\section{THE DOUBLE-EDGED EFFECT OF ENDOTOXIN IN ALLERGIC INFLAMMATION}

The bacterial lipopolysaccharide (LPS), the endotoxin of Gram-negative bacteria activating the TLR4 signaling pathway, is one of the most important microbial products which contaminates inhaled allergens as cockroachs, pollen and HDM. Allergen sensitization and development of atopic asthma were shown to be inversely related to endotoxin levels in house dust $[47,48]$. Endotoxin uptake also depends on the membrane-bound or soluble form of CD14 receptor [49]. Interestingly, polymorphisms of the genes encoding TLR4 and CD14 were found to influence the severity of asthma and its relation with endotoxin exposure [50-52].

However, epidemiological studies indicate that LPS exposure can exacerbate established asthma, probably by stimulating pro-inflammatory responses in the airways [47,53]. Animal models provided mechanistic insights into the role of LPS in the regulation of allergic asthma. In relation with the hygiene hypothesis, it appeared that the LPS dose is a determining factor in the course of allergic responses: low doses of inhaled LPS promoted Th2 re- 
sponses to the sensitizing antigen and eosinophilic inflammation, whereas high doses of LPS induced protective Th1 responses with, however [54] suppressed expression of Th2type cytokines and decreased eosinophilic inflammation and airway hyperresponsiveness but induced neutrophil inflammation [55]. Interestingly, the pro-Th2 adjuvant effect of low doses of LPS was found to depend on the Myd88-dependent signaling pathway, at least when administered by the airway route [56], by inducing the expression of inflammatory cytokines such as IL-6, IL-12 and TNF- $\alpha$ [54, 56-58].

\section{MEDIATION OF THE ALLERGIC RESPONSE BY AIRWAY EPITHELIAL-CELL-DC INTERACTIONS}

The action of TLR4 ligands was particularly well studied at the level of DCs because of their central role in the instruction of Th2 cells, which orchestrate the allergic reaction $[59,60]$. But in the context of allergic inflammation, epithelial cells also represent potential targets for such microbial products as airway epithelial cells have been shown to express TLR4 and can be activated by LPS. Consequently, although the epithelium was initially considered to function solely as a physical barrier, it is now considered as a central player in the Th2-cell sensitization process by mediating innate immune responses through cross-talk with DCs [32].

In response to allergens, TLR ligands or ambient particulate matter, airway epithelial cells trigger DC migration into epithelium via CCL20 (MIP-3 $\alpha$ ) production [32] as CCL20 is the only chemokine known to interact with CCR6 that is expressed by immature DC and Langerhans cells. The importance of CCR6 in allergic pulmonary inflammation has recently been demonstrated by using a cockroach antigen model with $\mathrm{CCR6}^{-1-}$ mice, showing that lack of CCR6 attenuates the allergic airway response to cockroach antigen [61]. Recent studies have shown that airway epithelial cells also influence DC control of Th differentiation locally via notably the production of the DC activator TSLP, IL-33 or IL-25. TSLP induces the expression of OX40 ligand on dendritic cells that triggers inflammatory Th2 differentiation in the absence of IL-12 through interactions with the $\mathrm{T}$ cell OX40 [62]. IL-33 was shown to enhance the production of IL- 5 and IL-13 by Th2 cells but not by Th1 cells in vitro [63]. IL-25 regulate also adaptive immunity by enhancing Th2 cytokine productions and induced AHR through activation NKT cells expressing IL-17RB [64,65]. A recent report showed that airway epithelial cells can produce IL-25 in response to an innate immune response to allergen [66].

\section{CONTAMINATING LPS IS ESSENTIAL FOR THE INDUCTION OF HDM ALLERGY THROUGH TLR4 SIGNALING}

Using a murine model of HDM allergic asthma (intranasal sensitizations with HDM extracts followed by airway challenge), it was lately demonstrated that mice deficient in MyD88 or TLR4 did not develop the common features of allergic asthma as airway inflammation, Th2 cytokine production and airways hyperreactivity [67]. This prevention of the allergen-specific Th2 response was associated with fewer OX40L-expressing myeloid dendritic cells in the draining lymph nodes during allergic sensitization. HDM-specific IL17 production and airway neutrophilia was attenuated in MyD88-/- but not TLR4-/- mice. These data suggested that the presence of microbial products in HDM extracts, more likely LPS, differentially regulate Th2- and Th17-mediated inflammation and activate distinct MyD88-dependent pattern recognition receptors. Whereas the contribution of TLR4 in HDM allergy was clearly evidenced in this report, the nature of the TLR4+ cells playing a major role in this process remained to be identified.

Very recently, Hammad et al. investigated the contribution of airway epithelial cells through TLR4 to allergic responses [68]. This group first demonstrated that TLR4 was expressed predominantly on pulmonary epithelial cells and alveolar macrophages and that TLR4 expression on airway structural cells was vital for effective migration of dendritic cells. Using mice with selective ablation of TLR4 expression on either lung structural cells or hematopoietic cells and that were treated with HDM extracts, these authors showed that TLR4 expression on lung structural cells, but not on DCs, is necessary and sufficient for DC activation in the lung and for the development of a robust eosinophilic and Th2 inflammatory response characterized by IL-5 and IL-13 production. TLR4 triggering on structural cells caused production of the innate pro-Th2 cytokines TSLP, GM-CSF, IL-25 and IL-33. The absence of TLR4 on structural cells, but not on hematopoietic cells, abolished HDM-driven allergic airway inflammation. Finally, inhalation of a TLR4 antagonist to target exposed epithelial cells suppressed the features of asthma, including bronchial hyperreactivity. The findings give epithelial cells a pivotal position in the generation of allergic inflammation through the activation of TLR4 signaling pathway by the contaminating LPS from HDM.

\section{OTHER IMMUNOSTIMULATORY FACTORS CON- TRIBUTING TO HDM ALLERGENICITY}

Other contaminating products than LPS might regulate the HDM-induced allergic diseases. Chitin, a widespread environmental biopolymer of $\mathrm{N}$-acetyl- $\beta$-D-glucosamine, part of the house dust mite exoskeleton, was shown to induce in mice the accumulation in tissue of IL-4-expressing innate immune cells, including eosinophils and basophils [69]. Moreover, Chitin induced a dose-dependent expression of acidic mammalian chitinase (AMCase) and eotaxin-3 mRNA, two pro-Th2 effector proteins in human sinonasal epithelial cells from patients with chronic rhinosinusitis with nasal polyps (CRSwNPs) [70].

The glucose-derived $\beta$-glucan polymers within the HDM extract were also newly shown to participate in the early events of allergic airway responses. Indeed, HDM induced CCL20 secretion in airway epithelial cells for the recruitment of immature DCs to the lung [71]. The effect was HDM-specific because other aeroallergens, such as ragweed and cockroach, fail to elicit this response. The CCL20 production was induced through a TLR-independent, proteaseindependent process but was dependent on $\beta$-glucan structures in the HDM extracts as other $\beta$-glucans could competitively inhibit the CCL20 secretion and as $\beta$-glucanase-treated HDM significantly failed to trigger the subsequent chemokine secretion. These effects could be more likely mediated by ligation of HDM-derived $\beta$-glucans to non-Toll PRRs such as the C-type lectin receptor dectin. 
Concomitantly, it was newly reported that HDM extracts stimulate cysteinyl leukotrienes (Cys-LTs) production by DC through recognition of Dectin-2 by glycan-derived molecules [72]. These compounds could be isolated by Concanavalin A affinity chromatography, suggesting a mannose- or glucoserich ligand. Cys-LTs through interactions with type 1 or 2 receptors, are potent mediators of bronchial smooth muscle constriction, vascular permeability, and pulmonary inflammation in bronchial asthma. This leukotriene generation through Dectin-2 activation was also dependent FcR $\gamma /$ Syk signaling pathway. This new pathway may activate innate immune cells to promote allergic inflammation. However, whether the critical glycan(s) binding to Dectin-2 is one of the many recognized glycoproteins in house dust mite remains to be determined.

It is noteworthy that HDM extracts promoted expression of cell surface c-KIT and its ligand, stem cell factor, on mouse DCs, resulting in sustained signaling downstream of KIT, upregulation of the Notch ligand Jagged-2, and finally IL-6 secretion [73]. The authors hypothesize that IL-6 upregulation could limit the Th1 response while promoting the Th2 and Th17 pathways. It must be pointed out that the role of IL- 6 was evidenced in Th2 and Th17 response elicited by allergens [74]. The nature of the compounds within the HDM extracts eliciting the IL-6 up-regulation at the level of DC remains to be identified. Transactivation of c-Kit by Cys-LTs, as already demonstrated in mast cells [75], could be another mechanism by which cys-LTs produced in response to house dust mite can modulate DC function in an autocrine fashion to promote allergic inflammation.

\section{BIOLOGICAL FUNCTIONS OF GROUP 1 AND 2 MITE ALLERGENS}

Group 1 and 2 mite allergens represent the most important allergenic molecules among HDM antigens as the vast majority of HDM-allergic patients develop specific IgE to these allergens and as $50-100 \%$ of IgE reactivity to HDM extract was directed towards these proteins [76-79]. Due to the wide cross-reactivity among mite species, active immunotherapy against Der $\mathrm{p} 1$ and Der $\mathrm{p} 2$ would potentially cure $80 \%$ of all mite-allergic patients globally [76,77]. Consequently, extensive studies for a greater understanding of the allergenicity of group 1 and $2 \mathrm{HDM}$ allergens could help to define new therapeutic strategies to block the allergic reaction induced by these antigens.

It is well known that the proteolytic activity of Der $\mathrm{p} 1$ can directly activate the innate and adaptive immune systems and, in this way, promotes Th2 sensitization [39 for a review]. Indeed, Der p 1 can cleave several cell-surface molecules, such as $\mathrm{CD} 23$ from $\mathrm{B}$ cells to up-regulate IgE production. Der p 1 can also cleave CD25 on T cells, CD40 and DC-SIGN from DC to polarize the immune system to the Th2 bias. Animal models demonstrated that the Der $\mathrm{p} 1$ proteolytic activity is crucial for allergic sensitization and can even facilitate sensitization to bystander antigens. Der $\mathrm{p} 1$ degrades airway antiproteases, such as $\alpha 1$-antitrypsin inhibitor, elafin, or secretory leukocyte protease inhibitor. In addition, Der $\mathrm{p} 1$ and Der $\mathrm{f} 1$ can inactivate lung surfactant proteins $\mathrm{A}$ and $\mathrm{D}$, which are known to inhibit the binding of inhaled allergens to cell-sequestered IgE. Der $\mathrm{p} 1$ can degrade tight-junction proteins in airway epithelium, which increased the permeability of the bronchial epithelium and consequently, facilitate allergen uptake by DC in subepithelial tissue. Moreover, Der p 1 can directly activate airway epithelial cells to promote proinflammatory cytokine production such as IL-6, IL-8 in a PAR2-independent manner [80].

Recently, it was demonstrated that Der p 1-induced degradation of CD40 resulted in reduced production of extracellular thiols by DC, and polarizing naive T cells towards Th2 because thiols appeared to be more critical for the generation of Th1 than Th2 cells [81].

The precise mechanism by which the major mite allergen Der p 2 favour Th2 allergic responses remained unresolved until recently. However, an elegant study clearly evidenced that Der p 2, by structural homology, acts as a functional homologue of MD2 (a lipid-binding, Toll-like receptor 4 (TLR4) signalling co-factor) to drive airway inflammation in a TLR4- dependent manner [82]. Indeed, the ability of Der $p$ 2 , purified from house dust mites and containing low levels of LPS, to activate cells in the absence of MD2 in a TLR4specific manner indicated that an LPS-Der p 2 complex might mimic the TLR4-activating properties of the LPSMD2 complex. Moreover, recombinant Der p 2 devoided of any LPS was inactive in the functional assays. Airway sensitization and challenge with Der p $2(0,1 \mu \mathrm{g})$, under conditions of very low levels of LPS exposure $(0,026 \mathrm{pg})$ normally would induce tolerance, led to experimental allergic asthma in wild type and MD-2-deficient, but not TLR4-deficient mice. Because Der $\mathrm{p} 2$ mimics the function of MD2, Der $\mathrm{p} 2$ consequently displays auto-adjuvant properties which are critical for the allergenicity of this mite allergen.

It must be pointed that many allergens, including Der $\mathrm{p} 2$, are members of the MD2-like lipid binding protein family [83], suggesting that the intrinsic adjuvant activity provided by associated lipids could also contribute to the allergenicity of these allergens.

Surprisingly, another study showed that Der p 2 stimulates airway smooth muscle cells in a TLR4-independent manner and leading to nuclear factor-kappa B (NF-kB), ERK, JNK activations, c-Fos expression and a high level of proinflammatory cytokines MCP-1, IL-6 and eotaxin expression which are important factors for the initiation of the Th2 allergic response [84]. Der p 2, on these cells, triggered the MyD88 signaling pathway through TLR2.

\section{CONCLUDING REMARKS}

HDM represents one of the most allergen carrier within industrialized countries. Although rapid progress in molecular biology of HDM allergens advanced our knowledge on the structure/function relationships of these antigens, several important questions remained unanswered about the HDM allergenicity. Some recent studies brought new insights into the critical role of contaminating LPS and $\beta$-glucans to control the initial Th2 polarization in response to HDM allergens. These non-allergenic adjuvant factors cooperate together with at least group 1 and 2 mite allergens, which display their own auto-adjuvant capacity, to stimulate not only DC but also airway epithelial cells to skew the immune response to Th2. On the basis of these findings, we proposed a new model of the innate initiation of the HDM-induced allergic response as illustrated in detail in Fig. (1). Future re- 


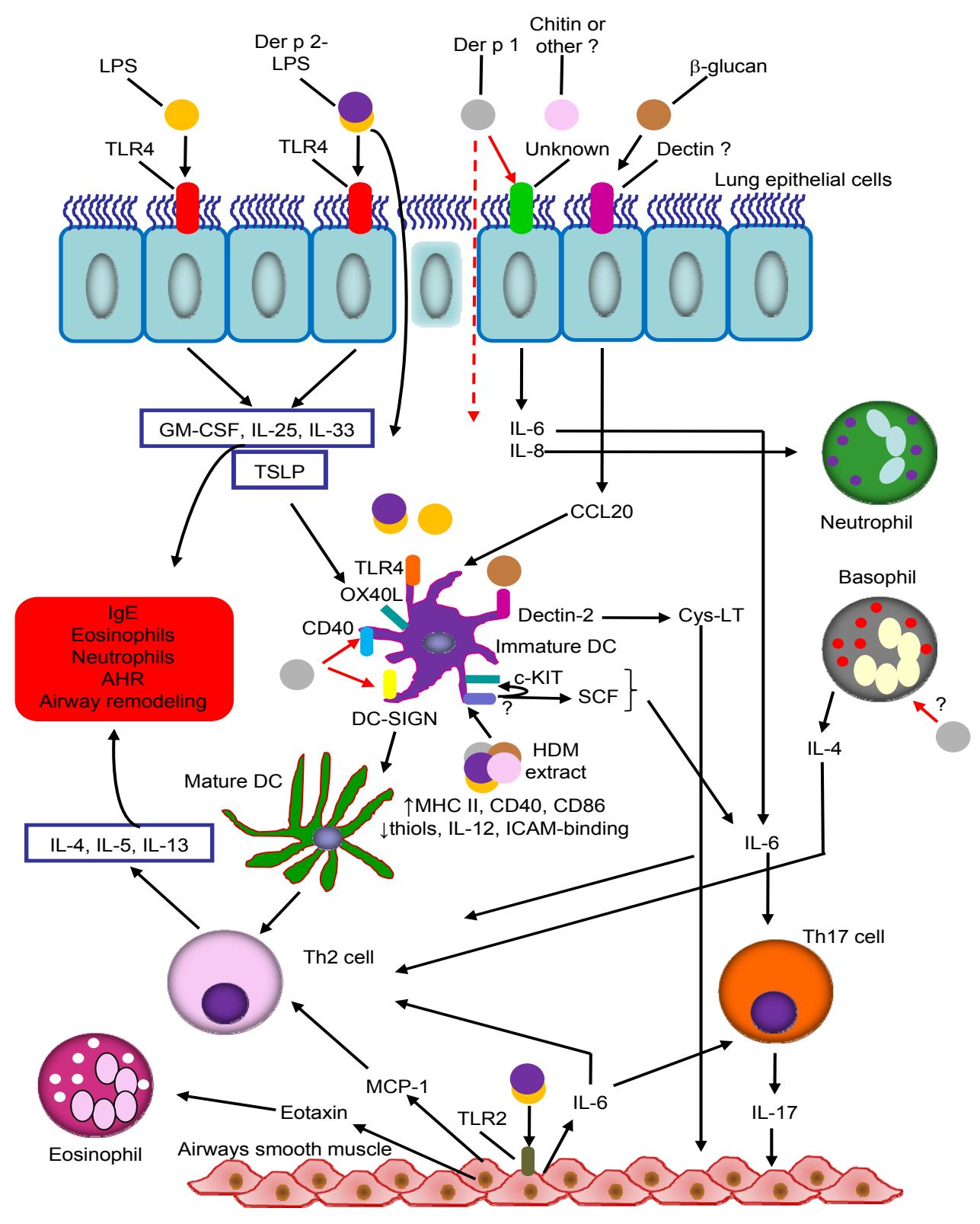

Fig. (1). Proposed model for the innate initiation of the allergic response induced by HDM.

Der $\mathrm{p} 1$ and the Der p 2-LPS complex, together with adjuvant-like contaminating molecules (including LPS, $\beta$-glucan or chitin), can activate unknown protease-sensitive receptors as well as PRR expressed by epithelial cells. Altogether, these stimulations lead to the production of chemokines and cytokines that not only attract and activate DCs but promote also an influx of inflammatory leukocytes to trigger eosinophilia, neutrophilia, airway remodeling and AHR. Thanks to the increasing permeability of the epithelial barrier following cleavages of tight junction proteins by Der p 1, submucosal DCs can be also directly activated by components of HDM. There is an immediate release of Cys-LT, potent mediators of bronchial smooth muscle constriction and IL-6. Activated DC will mature and migrate to mediastinal lymph nodes to present the allergen to naïve T cells. The cytokine milieu (notably TSLP, low IL-12 concentration) will drive the differentiation of naïve T cells into Th2 cells producing the cytokines IL-4, IL-5 and IL-13, the critical effectors of the salient features of asthma as the allergen-specific IgE antibody and the recruitment and activation of eosinophils. The presence of IL-6 will induce Th polarization skewing to Th17 cells which accentuate the airway pathology through notably the action of Th17 cytokines as IL-17 on the airway smooth muscles.

TLR, Toll-like receptor; CCL, CC-chemokine ligand; GM-CSF, granulocyte/macrophage colony stimulating factor; TSLP, thymic stromal lymphopoietin; Cys-LT, cysteinyl leukotriene; SCF, stem cell factor; DC-SIGN, dendritic cell-specific intercellular adhesion molecule 3grabbing nonintegrin; MCP-1, monocyte chemotactic protein-1.

search should try, using purified recombinant mite allergens, to elucidate whether exposure to these individual mite allergens are able to stimulate the production of the pro-Th2 cytokines such as TSLP, IL-25, IL-33 at the level of the airway structural as well as innate immune cells. Extensive studies should also focus on the putative additional factors from HDM which could influence the outcome of the responses to HDM allergens. The characterization of environmental compounds in HDM could thus open the door to new therapeutic approaches. 


\section{REFERENCES}

[1] Asher MI, Montefort S, Bjorksten B, et al. ISAAC Phase Three Study Group. Worldwide time trends in the prevalence of symptoms of asthma, allergic rhinoconjunctivitis, and eczema in childhood: ISAAC phases one and three repeat multicountry crosssectional surveys. Lancet 2006; 368: 733-43.

[2] Galli SJ, Tsai M, Piliponsky AM. The development of allergic inflammation. Nature 2008; 454: 445-54.

[3] Zock JP, Heinrich J, Jarvis D, et al. Distribution and determinants of house dust mite allergens in Europe: the European Community Respiratory Health Survey II. J Allergy Clin Immunol 2006; 118: 682-90.

[4] Thomas WR, Smith WA, Hales BJ, Mills KL, O'Brien RM. Characterization and immunobiology of house dust mite allergens. Int Arch Allergy Immunol 2002; 129: 1-18.

[5] Batard T, Hrabina A, Bi XZ, et al. Production and proteomic characterization of pharmaceutical-grade Dermatophagoides pteronyssinus and Dermatophagoides farinae extracts for allergy vaccines. Int Arch Allergy Immunol 2006; 140: 295-305.

[6] Weghofer M, Dall'Antonia Y, Grote M, et al. Characterization of Der p 21, a new important allergen derived from the gut of house dust mites. Allergy 2008; 63: 758-67.

[7] Fernandez-Caldas E, Puerta L, Caraballo L, Lockey RF. Mite allergens. J Clin Allergy Immunol 2008; 21: 161-82.

[8] Thunberg S, Akdis M, Akdis CA, et al. Immune regulation by CD4+CD25+ T cells and interleukin-10 in birch pollen allergic patients and non-allergic controls. Clin Exp Allergy 2007; 37: 112736.

[9] Schaub B, Liu J, Höppler S, et al. Impairment of T regulatory cells in cord blood of atopic mothers. J Allergy Clin Immunol 2008; 121: 1491-9.

[10] Larche M, Robinson DS, Kay AB. The role of T lymphocytes in the pathogenesis of asthma. J Allergy Clin Immunol 2003; 111: 450-63.

[11] Walker C, Bode E, Boer L, Hansel TT, Blaser K, Virchow JC Jr. Allergic and nonallergic asthmatics have distinct patterns of $\mathrm{T}$ cell activation and cytokine production in peripheral blood and bronchoalveolar lavage. Am Rev Respir Dis 1992; 146: 109-15.

[12] Del Prete GF, De Carli M, D'Elios MM, et al. Allergen exposure induces the activation of allergen-specific Th2 cells in the airway mucosa of patients with allergic respiratory disorders. Eur J Immunol 1993; 23: 1445-9.

[13] Robinson DS, Hamid Q, Ying S, et al. Predominant TH2-like bronchoalveolar T-lymphocyte population in atopic asthma. N Engl $\mathbf{J}$ Med 1992; 326: 298-304.

[14] Saha SK, Berry MA, Parker D, et al. Increased sputum and bronchial biopsy IL-13 expression in severe asthma. J Allergy Clin Immunol 2008; 121: 685-91.

[15] Wills-Karp M, Luyimbazi J, Xu X, et al. Interleukin-13: central mediator of allergic asthma. Science 1998; 282: 2258-61.

[16] Foster PS, Hogan SP, Ramsay AJ, Matthaei KI, Young IG. Interleukin 5 deficiency abolishes eosinophilia, airways hyperreactivity, and lung damage in a mouse asthma model. J Exp Med 1996; 183: 195-201.

[17] Brusselle G, Kips J, Joos G, Bluethmann H, Pauwels R. Allergeninduced airway inflammation and bronchial responsiveness in wildtype and interleukin-4-deficient mice. Am J Respir Cell Mol Biol 1995; 12: 254-9.

[18] Kips JC, Brusselle GG, Joos GF, et al. Importance of interleukin-4 and interleukin-12 in allergen-induced airway changes in mice. Int Arch Allergy Immunol 1995; 107: 115-8.

[19] Akdis M, Akdis CA. Mechanisms of allergen-specific immunotherapy. J Allergy Clin Immunol 2007; 119: 780-91.

[20] Akdis M. Healthy immune response to allergens: T regulatory cells and more. Curr Opin Immunol 2006; 18: 738-44.

[21] Larche M, Akdis CA, Valenta R. Immunological mechanisms of allergen-specific immunotherapy. Nat Rev Immunol 2006; 6: 76171.

[22] Kang CM, Jang AS, Ahn MH, et al. Interleukin-25 and interleukin13 production by alveolar macrophages in response to particles. Am J Respir Cell Mol Biol 2005; 33: 290-6.

[23] Wang YH, Angkasekwinai P, Lu N, et al. IL-25 augments type 2 immune responses by enhancing the expansion and functions of TSLP-DC-activated Th2 memory cells. J Exp Med 2007; 204: 1837-47.
[24] Dillon SR, Sprecher C, Hammond A, et al. Interleukin 31, a cytokine produced by activated $\mathrm{T}$ cells, induces dermatitis in mice. Nat Immunol 2004; 5: 752-60.

[25] Bilsborough J, Leung DY, Maurer M, et al. IL-31 is associated with cutaneous lymphocyte antigen-positive skin homing $\mathrm{T}$ cells in patients with atopic dermatitis. J Allergy Clin Immunol 2006; 117: 418-25.

[26] Kakkar R, Lee RT. The IL-33/ST2 pathway: therapeutic target and novel biomarker. Nat Rev Drug Discov 2008; 7: 827-40.

[27] Romagnani S. Immunologic influences on allergy and the TH1/TH2 balance. J Allergy Clin Immunol 2004; 113: 395-400.

[28] Afshar R, Medoff BD, Luster AD. Allergic asthma: a tale of many T cells. Clin Exp Allergy 2008; 38: 1847-57.

[29] Blanco P, Palucka AK, Pascual V, Banchereau J. Dendritic cells and cytokines in human inflammatory and autoimmune diseases. Cytokine Growth Factor Rev 2008; 19: 41-52.

[30] Kitani A, Xu L. Regulatory T cells and the induction of IL-17. Mucosal Immunol 2008; 1(Suppl 1): S43-6.

[31] Willart MA, Lambrecht BN. The danger within: endogenous danger signals, atopy and asthma. Clin Exp Allergy 2009; 39: 12-9.

[32] Hammad H, Lambrecht BN. Dendritic cells and epithelial cells: linking innate and adaptive immunity in asthma. Nat Rev Immunol 2008; 8: 193-204.

[33] Banchereau J, Steinman RM. Dendritic cells and the control of immunity. Nature 1998; 392: 245-52.

[34] Reis e Sousa C. Dendritic cells in a mature age. Nat Rev Immunol 2006; 6: 476-83.

[35] de Heer HJ, Hammad H, Soullie T, et al. Essential role of lung plasmacytoid dendritic cells in preventing asthmatic reactions to harmless inhaled antigen. J Exp Med 2004; 200: 89-98.

[36] de Jong EC, Smits HH, Kapsenberg ML. Dendritic cell-mediated T cell polarization. Springer Semin Immunopathol 2005; 26: 289307.

[37] Annunziato F, Cosmi L, Liotta F, Maggi E, Romagnani S. The phenotype of human Th17 cells and their precursors, the cytokines that mediate their differentiation and the role of Th17 cells in inflammation. Int Immunol 2008; 20: 1361-8.

[38] Sokol CL, Barton GM, Farr AG, Medzhitov R. A mechanism for the initiation of allergen-induced $\mathrm{T}$ helper type 2 responses. Nat Immunol 2008; 9: 310-8.

[39] Shakib F, Ghaemmaghami AM, Sewell HF. The molecular basis of allergenicity. Trends Immunol 2008; 29: 633-42.

[40] Traidl-Hoffmann C, Mariani V, Hochrein H, et al. Pollenassociated phytoprostanes inhibit dendritic cell interleukin-12 production and augment $\mathrm{T}$ helper type 2 cell polarization. J Exp Med 2005; 201: 627-36.

[41] Dahl ME, Dabbagh K, Liggitt D, Kim S, Lewis DB. Viral-induced $\mathrm{T}$ helper type 1 responses enhance allergic disease by effects on lung dendritic cells. Nat Immunol 2004; 5: 337-43.

[42] D'Hulst AI, Vermaelen KY, Brusselle GG, Joos GF, Pauwels RA. Time course of cigarette smoke-induced pulmonary inflammation in mice. Eur Respir J 2005; 26: 204-13.

[43] Akira S, Uematsu S, Takeuchi O. Pathogen recognition and innate immunity. Cell 2006; 124: 783-801.

[44] Erard F, Ryffel B. Toll like receptor - potential drug targets in infectious disease. Infect Disord Drug Targets 2008; 8: 221-31.

[45] van Kooyk Y. C-type lectins on dendritic cells: key modulators for the induction of immune responses. Biochem Soc Trans 2008; 36: 1478-81.

[46] Shaw MH, Reimer T, Kim YG, Nuñez G. NOD-like receptors (NLRs): bona fide intracellular microbial sensors. Curr Opin Immunol 2008; 20: 377-82.

[47] Braun-Fahrlander C, Riedler J, Herz U, et al. Environmental exposure to endotoxin and its relation to asthma in school-age children. N Engl J Med 2002; 347: 869-77.

[48] Gereda JE, Leung DY, Thatayatikom A, et al. Relation between house-dust endotoxin exposure, type $1 \mathrm{~T}$-cell development, and allergen sensitisation in infants at high risk of asthma. Lancet 2000; 355: 1680-3.

[49] Pugin J, Heumann ID, Tomasz A, et al. CD14 is a pattern recognition receptor. Immunity 1994; 1: 509-16.

[50] Werner M, Topp R, Wimmer K, et al. TLR4 gene variants modify endotoxin effects on asthma. J Allergy Clin Immunol 2003; 112: 323-30. 
[51] Yang IA, Barton SJ, Rorke S, et al. Toll-like receptor 4 polymorphism and severity of atopy in asthmatics. Genes Immun 2004; 5: 41-5.

[52] Yang IA, Holgate ST, Holloway JW. Toll-like receptor polymorphisms and allergic disease: interpreting the evidence from genetic studies. Clin Exp Allergy 2004; 34: 163-6.

[53] Michel O, Duchateau J, Sergysels R. Effect of inhaled endotoxin on bronchial reactivity in asthmatic and normal subjects. J Appl Physiol 1989; 66: 1059-64.

[54] Eisenbarth SC, Piggott DA, Huleatt JW, Visintin I, Herrick CA, Bottomly K. Lipopolysaccharide-enhanced, toll-like receptor 4dependent $\mathrm{T}$ helper cell type 2 responses to inhaled antigen. J Exp Med 2002; 196: 1645-51.

[55] Lundy SK, Berlin AA, Lukacs NW. Interleukin-12-independent down-modulation of cockroach antigen-induced asthma in mice by intranasal exposure to bacterial lipopolysaccharide. Am J Pathol 2003; 163: 1961-8.

[56] Piggott DA, Eisenbarth SC, Xu L, et al. MyD88-dependent induction of allergic Th2 responses to intranasal antigen. J Clin Invest 2005; 115: 459-67.

[57] Tsan MF, Baochong G. Pathogen-associated molecular pattern contamination as putative endogenous ligands of Toll-like receptors. J Endotoxin Res 2007; 13: 6-14.

[58] Bortolatto J, Borducchi E, Rodriguez D, et al. Toll-like receptor 4 agonists adsorbed to aluminium hydroxide adjuvant attenuate ovalbumin-specific allergic airway disease: role of MyD88 adaptor molecule and interleukin-12/interferon-gamma axis. Clin Exp Allergy 2008; 38: 1668-79.

[59] Duez C, Gosset P, Tonnel AB. Dendritic cells and Toll-like receptors in allergy and asthma. Eur J Dermatol 2006; 16: 12-6.

[60] Eisenbarth SC, Piggott DA, Bottomly K. The master regulators of allergic inflammation: dendritic cells in Th2 sensitization. Curr Opin Immunol 2003; 15: 620-6.

[61] Lukacs NW, Prosser DM, Wiekowski M, Lira SA, Cook DN. Requirement for the chemokine receptor CCR6 in allergic pulmonary inflammation. J Exp Med 2001; 194: 551-5.

[62] Liu YJ. Thymic stromal lymphopoietin and OX40 ligand pathway in the initiation of dendritic cell-mediated allergic inflammation. $\mathbf{J}$ Allergy Clin Immunol 2007; 120: 238-44.

[63] Kato A, Schleimer RP. Beyond inflammation: airway epithelial cells are at the interface of innate and adaptive immunity. Curr Opin Immunol 2007; 19: 711-20.

[64] Stock P, Lombardi V, Kohlrautz V, Akbari O. Induction of airway hyperreactivity by IL-25 is dependent on a subset of invariant NKT cells expressing IL-17RB. J Immunol 2009; 182: 5116-22.

[65] Terashima A, Watarai $\mathrm{H}$, Inoue $\mathrm{S}$, et al. A novel subset of mouse NKT cells bearing the IL-17 receptor B responds to IL-25 and contributes to airway hyperreactivity. J Exp Med 2008; 205: 2727-33.

[66] Angkasekwinai P, Park H, Wang YH, et al. Interleukin 25 promotes the initiation of proallergic type 2 responses. J Exp Med 2007; 204: 1509-17.

[67] Phipps S, Lam CE, Kaiko GE, et al. Toll/IL-1 signaling is critical for house dust mite-specific Th1 and Th2 responses. Am J Respir Crit Care Med 2009; 179: 883-93.

[68] Hammad H, Chieppa M, Perros F, Willart MA, Germain RN, Lambrecht BN. House dust mite allergen induces asthma via Toll-like receptor 4 triggering of airway structural cells. Nat Med 2009; 15: 410-6.

[69] Reese TA, Liang HE, Tager AM, et al. Chitin induces accumulation in tissue of innate immune cells associated with allergy. Nature 2007; 447: 92-6.

[70] Lalaker A, Nkrumah L, Lee WK, Ramanathan M, Lane AP. Chitin stimulates expression of acidic mammalian chitinase and eotaxin-3 by human sinonasal epithelial cells in vitro. Am J Rhinol Allergy 2009; 23: 8-14.

[71] Nathan AT, Peterson EA, Chakir J, Wills-Karp M. Innate immune responses of airway epithelium to house dust mite are mediated through beta-glucan-dependent pathways. J Allergy Clin Immunol 2009; 123: 612-8.

[72] Barrett NA, Maekawa A, Rahman OM, Austen KF, Kanaoka Y. Dectin-2 recognition of house dust mite triggers cysteinyl leukotriene generation by dendritic cells. J Immunol 2009; 182: 1119-28.

[73] Krishnamoorthy N, Oriss TB, Paglia M, et al. Activation of c-Kit in dendritic cells regulates $\mathrm{T}$ helper cell differentiation and allergic asthma. Nat Med 2008; 14: 565-73.

[74] Kolls JK, Linden A. Interleukin-17 family members and inflammation. Immunity 2004; 21: 467-76.

[75] Jiang Y, Kanaoka Y, Feng C, Nocka K, Rao S, Boyce JA. Interleukin 4-dependent mast cell proliferation requires autocrine/intracrine cysteinyl leukotriene-induced signaling. J Immunol 2006; 177: 2755-9.

[76] Van Der Zee JS, Van Swieten P, Jansen HM, Aalberse RC. Skin tests and histamine release with P1-depleted Dermatophagoides pteronyssinus body extracts and purified P1. J Allergy Clin Immunol 1988; 81: 884-95.

[77] Meyer CH, Bond JF, Chen MS, Kasaian MT. Comparison of the levels of the major allergens Der p I and Der p II in standardized extracts of the house dust mite, Dermatophagoides pteronyssinus. Clin Exp Allergy 1994; 24: 1041-8.

[78] Pittner G, Vrtala S, Thomas WR, et al. Component-resolved diagnosis of house-dust mite allergy with purified natural and recombinant mite allergens. Clin Exp Allergy 2004; 34: 597-603.

[79] Hales BJ, Martín AC, Pearce LJ, et al. IgE and IgG anti-house dust mite specificities in allergic disease. J Allergy Clin Immunol 2006 118: 361-7.

[80] Adam E, Hansen KK, Astudillo Fernandez O, et al. The house dust mite allergen Der $\mathrm{p} 1$, unlike Der $\mathrm{p} 3$, stimulates the expression of interleukin-8 in human airway epithelial cells via a proteinaseactivated receptor-2-independent mechanism. J Biol Chem 2006; 281: 6910-23.

[81] Hasan AA, Ghaemmaghami AM, Fairclough L, Robins A, Sewell HF, Shakib F. Allergen-driven suppression of thiol production by human dendritic cells and the effect of thiols on $\mathrm{T}$ cell function. Immunobiology 2009; 214: 2-16.

[82] Trompette A, Divanovic S, Visintin A, et al. Allergenicity resulting from functional mimicry of a Toll-like receptor complex protein. Nature 2009; 457: 585-8

[83] Inohara N, Nunez G. ML-a conserved domain involved in innate immunity and lipid metabolism. Trends Biochem Sci 2002; 27: 219-21.

[84] Chiou YL, Lin CY. Der p2 activates airway smooth muscle cells in a TLR2/MyD88-dependent manner to induce an inflammatory response. J Cell Physiol 2009; 220: 311-8.

(C) Alain Jacquet; Licensee Bentham Open.

This is an open access article licensed under the terms of the Creative Commons Attribution Non-Commercial License (http://creativecommons.org/licenses/by-nc/3.0/) which permits unrestricted, non-commercial use, distribution and reproduction in any medium, provided the work is properly cited. 